\title{
An Analysis of Good Governance in the Health System
}

\author{
Faranak Jafari (iD) ${ }^{1}$, Kamran Hajinabi $(\mathbb{D})^{1,{ }^{*}}$, Katayoun Jahangiri $\mathbb{i D}^{2}$ and Leila Riahi ${ }^{1}$ \\ ${ }^{1}$ Department of Health Services Administration, Science and Research Branch, Islamic Azad University, Tehran, Iran \\ ${ }^{2}$ Department of Health in Emergencies, Faculty of Health Safety and Environment, Shahid Beheshti University of Medical Sciences, Tehran, Iran \\ "Corresponding author: Assistant Professor of the Department of Health Services Administration, Science and Research Branch, Islamic Azad University, Tehran, Iran. Email: \\ khajinabi@yahoo.com
}

Received 2018 May 23; Accepted 2018 June 23.

\begin{abstract}
Context: Good governance has been discussed as a new concept for poverty alleviation and economic development by global organizations, but this concept has been neglected in the health system. Therefore, this study was conducted with the goal of analyzing good governance in the health system.

Evidence Acquisition: This was a descriptive study with systematic review method conducted at the medical bases of Medline, Scopus, Elsevier, PubMed, Ovid, CINAHEL, ScienceDirect, Springer and Web of Science and after screening at different stages, articles were evaluated and analyzed with inclusion criteria.

Results: Among 360 studies, 10 cases had inclusion criteria. Three out of ten studies had evaluated the aspects of good governance in the health system and seven cases were discussed in the study of governance frameworks of health systems.

Conclusions: Despite the emphasis of this study, using eight dimensions of participation, including: Rule of law, transparency, accountability, equality, efficiency and effectiveness, responsibility and the formation of general consensus (consensus) in analyzing good governance of countries, designing a native model of good governance in the health system in different societies, is essential.
\end{abstract}

Keywords: Good Governance, Governance of the Health System, Good Governance Indicators

\section{Context}

Good governance is a system of values, policies and institutions that society controls it through public, private and civil sections, carries out economy, politics and social affairs (1), through which citizens, groups and institutions pursue their civil rights and fulfill their obligations and balance their differences (2).

Therefore, according to the concepts and discussions about good governance, it can be considered as a subject focused on finding a model and a new combination of cooperation between the three sectors of government, civil society and the private sector. In this model, three perspectives are considered which are including: Civil society as citizen's rights advocate, private sector as the production agent in enhancing investment and GDP growth, and finally the role of the government as facilitator of public activities for sustainable development in the environmental provision (3).

As some authors have pointed out and according to the United Nations national development plan document, the goal of good governance is to achieve sustainable human development that focuses on reducing poverty, creating jobs and sustainable prosperity, protecting the environmental and restoring the environment, and women's growth and development. In fact, it is assumed that all these things will be achieved through good governance (4).

Today, the issue of development is attracted the attention of many countries, and simply, development is nothing but satisfying the condition of the people. On the other hand, human is the main criterion for different aspects of development and his health are very important for leaders in development programs. However, many health systems in the world are still poorly managed and many countries are facing a lot of problems for decision-making in their health care sector, therefore, significant changes have been considered in the health and treatment services system (5).

Regarding how the government and society mutually collaborate to achieve the goals of government, as well as, focus on health issues and determinants, its views and approaches to focus on the health system governance, strengthening it and the need for health cooperation and other sectors (private, government, and citizens) is changing to achieve good governance in the health system. Accordingly, health system reforms and its governance means are focusing on providing accurate services based on the needs of applicants through hospitals and health service providers is a global phenomenon which is highly 
regarded. Health governance refers to the evaluation of the role of laws and regulations and policies in maintaining and improving the health of the community and, it is a tool that society generally uses to ensure the conditions that citizens can live with the highest levels of health and well-being (1).

The remarkable point is that governance is not just about the state, but the overall responsibility of society is at the macro level. The main stakeholders of society, including: Businesses, employees, universities, media and civil society have a significant effect on health and strengthening the energy of these sectors and coordinating their activities are essential for the health of the community (6). Political wish and institutional capacity are needed for good governance. At the first levels of government, the existence of political wish will provide the necessary capacity for reforming the health care system. Of course, realizing this issue requires high-level monitoring and supervision, which requires proportional institutional capacity. Political wish is considered from the perspective that the subject of decentralization is considered as one of the main foundations of good governance in health (4).

Brinkerhoff (2014) has evaluated the role of good governance in strengthening health systems and pointed to three gaps in health and governance problems. These three gaps are: (1) The gap between good governance and existing capacities; (2) the difference between formal and informal governance; (3) neglecting the dynamics of social political power. He discussed about the reforms in the health sector of China, the resource management of Brazil and Lesotho hospital reforms and concluded that the suitable relationship between social actors and the government is the main factor in the good governance model in the health sector. He also mentioned to fill the gap between social and political actors and provide practical and appropriate guidance with emphasis on the political realities of each country in order to strengthen health systems (7). Using the variables defined by Kauffman et al. for good governance, Lazarova and Mosca (2007) have evaluated the role of these variables on health status. The result of this study showed that good governance is closely linked to life expectancy. But the problem with this study was that only quantitative variables have been used to express health status, while good governance often shows qualitative variables among different countries (8). The concept of good governance in the international health system has been increasingly considered according to the complexity of the health system and the effect of good governance and policies in promoting health and reducing the costs of the health system. But its conceptualization is still in its beginning and needs to be evaluated (1). Therefore, by analyzing good governance in the health system, this study aimed at highlighting the importance of considering the indicators and dimensions of the health system's challenges.

\section{Evidence Acquisition}

\subsection{Search Strategy and Inclusion Criteria}

This study was a descriptive systematic review. In this study, two inclusion criteria were determined. Papers and reports about good governance were reviewed for the first objective (identification of the studies about good governance dimensions). Then, for the second objective (identifying studies of the dimensions about good governance in the health system), the dimensions of good governance were evaluated in governmental management and the health system (Table 1). Statistical society of this systematic study included all English language articles and reports in the period of 1994 (the year in which the term "Governance" was introduced by the World Bank) until 2018, which were searched at Medline, Scopus, Elsevier, PubMed, Ovid, CINAHEL, ScienceDirect, Springer, Web of Science. For example, keywords were searched for good governance (dimensions, components, barriers and good governance indicators) in the health system (challenges, barriers and dimensions of good governance in the health system) and all terms in the abstract, keywords, titles, and text words. In the Advance Search and Pub Med database sections, using the history and past searches and combining them, the search was made for good governance articles.

\section{Results}

In this study, 321 articles were obtained through a database search and 39 reports from other sources. 10 of them had inclusion criteria (Figure 1 and Table 2). Three studies among them had evaluated the dimensions of good governance in the health system and seven cases had discussed in the framework of health system governance.

\subsection{Findings of Good Governance in the Health Sector}

Smith et al., using cybernetic theory, developed a framework for good governance and implemented it at the national level of seven health systems in high-income regions such as Australia, England, Germany, the Netherlands, Norway, Sweden and Switzerland. This framework has consisted of three key governance groups (priority setting, responsiveness and performance monitoring) which are the guiding criterion for hierarchy evaluation, market and network monitoring. An important lesson learned by the authors is that the existence of eligibility and capacity at different levels of the health system is important for successful implementing of good leadership and governance (5).

Kirigia and Kirigia (9) have made some improvements in the framework of good governance which were in line with the "governance for health development" in the African-Asian region and designed the new concept of 


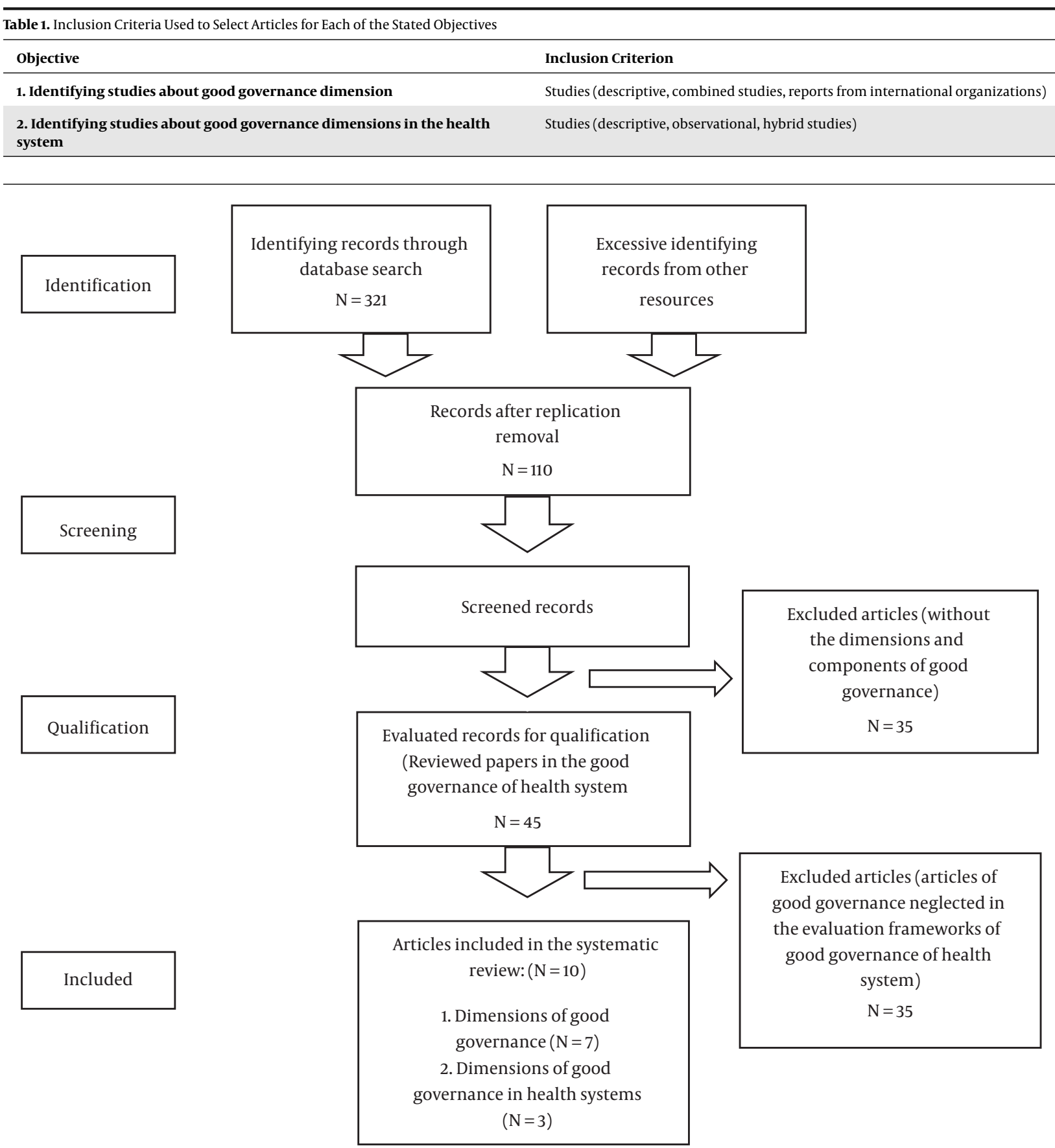

Figure 1. Study selection method and the results (adapted from PRISMA, in 2009)

"good governance in health development" in line with the African-Asian region. In this study, 10 performances and 42 sub-systems developed the governance index for health development. The authors emphasized that health development cannot be achieved without political and economic stability in the form of a national economic development plan or poverty reduction strategy, the medium-term cost framework of governance and the process of non-violence selection. The authors stated that the individual and collective privileges of the governance need to be improved 


\begin{tabular}{|c|c|}
\hline Expert or International Organization & Good Governance Dimensions \\
\hline World Bank Institute/global governance indicators & $\begin{array}{l}\text { The right to comment and answer, political stability and lack of violence, governance } \\
\text { effectiveness, legislative quality, rule of law, corruption control }\end{array}$ \\
\hline Kirigia and Kirigia (2011) & $\begin{array}{l}\text { Public health management, health regulations, existence of health laws, community } \\
\text { participation and responsiveness, domestic and foreign health cooperation, use of } \\
\text { country procurement and public financial management systems, horizontal and public } \\
\text { equity in health systems, efficiency in allocation and use resources, accountability and } \\
\text { transparency in health development, decision-making based on evidence, ethical } \\
\text { practices in research and provision of health services, economic and political stability }\end{array}$ \\
\hline Islam (2007) & $\begin{array}{l}\text { Provision of services, health workforce, health information systems, access to essential } \\
\text { medicines, financing, and leadership }\end{array}$ \\
\hline United Nations & $\begin{array}{l}\text { Participation, rule of law, transparency, accountability, universal orientation, efficiency } \\
\text { and effectiveness, accountability, strategic attitude }\end{array}$ \\
\hline Mo Ibrahim Foundation/African governance index & $\begin{array}{l}\text { Security and rule of law, participation and human rights, economic sustainability, human } \\
\text { development }\end{array}$ \\
\hline Siddiqi et al. (2009) & $\begin{array}{l}\text { Strategic vision, consensus participation and orientation, rule of law, transparency and } \\
\text { accountability, equality of rights and constitutionality, effectiveness and efficiency, } \\
\text { responsibility, intelligence and information, ethical principles }\end{array}$ \\
\hline The World Bank (1994) and Asian Development Bank (1995) & Capacity building, accountability, participation, transparency, predictability \\
\hline UN Economic and Social Commission for Asia and the Pacific (2002) & $\begin{array}{l}\text { Participation, equality before law, transparency, accountability, general satisfaction, } \\
\text { equality, efficiency and effectiveness, accountability, strategic vision }\end{array}$ \\
\hline Kaufmann et al. (2005) & $\begin{array}{l}\text { Audience and accountability, political stability and avoidance of violence, government } \\
\text { effectiveness, regulatory quality, equality of law, corruption control }\end{array}$ \\
\hline
\end{tabular}

to warn regional policymakers.

This study has been identified as the only framework which tried to determine the governance using regulatory measures such as existence of specific policies or guidelines. The authors provided a scoring system that measured the rate of governance of each performance with a score of very poor (0\%) to excellent (100\%). This scoring allowed the evaluators to identify areas which were requiring improvement, and the overall indicator showed the general state of governance in any country that they wanted to calculate about it (9).

Siddiqi et al. generalized good governance to 10 components: Strategic vision, participation and general orientation, rule of law, transparency, accountability, equality and comprehensiveness, efficiency and effectiveness, accountability, information and ethics (10).

Based on the dimensions of good governance which have been explained by the economic, social, Asia-Pacific commission and the United Nations development program, The World Health Organization has evaluated the good governance indicators in different countries in eight dimensions, including: Participation, rule of law, transparency, accountability, equity, efficiency and effectiveness, responsibility and formation of the general consensus (consensus). Although, these dimensions have been discussed in government administration, there are studies about the possibility of using them in the health system
(11). Accordingly, these dimensions have been discussed in the analysis of the health system in this study.

\subsection{Dimensions of Good Governance in the Health System}

\subsubsection{Social Participation}

More attention has been attracted to the discussion of the participation of people in the modern society in recent decades. Although, past generations considered the meaning of public participation as the knowledge of individuals about decision-makers, it was thought that these terms were purely one-way, from the directors to the community, but nowadays and in the current context, new concepts of participation have been proposed that offered a variety of dimensions (8).

Improving the sense of responsibility and consciousness of people towards individual and collective health are the most prominent benefits of social participation that have been addressed in various sources. Another advantage of gaining power is the through the creation of new skills and resource control capabilities (7). Indeed, participators train themselves to control their own fate and provide equal opportunities between themselves and providers of health services. In the process of participation in health, the opportunity for distributing health knowledge in the community has been created and led to the internal acquisition of skill and mastery in public health 
promotion activities. The involvement and active participation of local people will reduce the sense of affection and, the sense of power and domination of official organizations will be disappeared. All these positively have an effect on the health of the people and society (12).

\subsubsection{Rule of Law}

The right to health includes the conditions that governments are committed to provide them for creating the possibility of a healthy lifestyle. The right to health, as a fundamental human right, has a special place in a national and international document and is one of the accepted principles in all countries. The government's commitment to promote the right to health, such as any other human right, has three dimensions:

- Commitment to respect: Means that the state acts in a way that saves the freedom of the individual's actions and his dignity. In accordance to the right to health, this applies through government laws and policies.

- Commitment to support: Under this commitment, the rights of individuals are respected and not only the government should not interfere, but also prevent thirdparty intervention. This commitment means that governments should try to minimize the health risks and take the necessary measures to protect the right of public health to interfere with third parties.

- Commitment to play: Under this commitment, governments are required to take actions that allow people to be healthy in practice (13).

Many studies emphasize the importance of the rule of law in the health and development of countries. In Sweden, three basic principles apply in all Swedish health care systems which have been implemented at all levels of health in Sweden:(1)Human dignity (equality of all people, regardless of their situation in the society); (2) need and correlation (priority of treatment for people with greater need); (3) cost-effectiveness with benchmark for improving health and quality of life. However, despite the fact that in many countries the rights of citizens in health matters are well considered in the laws of the health system, there is no guarantee for its implementation. As Kumssa and Mbeche in a study entitled "the role of institutions in the development of African countries" concluded that the poor implementation of the rule of law, corruption, management weakness, absence of a strong civil society and political interference are the most important obstacles for the development of these countries (14).

\subsubsection{Transparency}

In contemporary times, increasing public awareness, growth of health information, justice and participatory has caused that the clarity of activities and affairs transformed to public value and demand. This trend has been shaped in societies developed through multilateral and gradual changes, in line with changing economic, political and cultural structures. As a result of this process, respect to human rights and realization of justice have exceeded the level of individual morality and have become part of the moral responsibility of organizations. "The moral responsibility of organizations is the commitment to do the right, just and fair thing and prevent harm" (15).

In the UK, in order to improve the patient's therapeutic efficacy and safety, the electronic record of patient file has been on the agenda since 1997. In 2003, the national health service system has introduced a plan to inform patients about the inconvenience or neglect of the causes of injury, and designed a plan including health care, apologies and financial compensation in order to compensate for the damage (16). In Sweden, in order to improve transparency, health and treatment reforms have been also taken since 1990s (17). In the same vein, the European Union in 1991 and the United States in 1998 approved the freedom of information access act, which provided the transparency of information. In some advanced countries, self-disclosure is a way of increasing transparency. In the United States, in 2001 , the integrated accreditation board for health care organizations implemented a plan for uncovering the unpredictable results as a type of accreditation criterion. In 2003, the Australian council on safety and quality of health care considered standards for open communication in public and private hospitals at the national level (18).

\subsubsection{Responsiveness}

Responsiveness is important for policy makers and managers as one of the main goals of the health system. Good health systems around the world are looking for ways to make patients and society more responsive. In the health system, responsiveness includes a common set of eight dimensions, including: Quick attention, respect to people's dignity, clarity of communication, autonomy, confidentiality of personal information, choice of provider, quality of basic services and access to family and social support (19). In this regard, in recent years, changes have been made in the health system of many countries which have led to the satisfaction of patients. For example, the existence of the Australian patients' rights advocacy council, ongoing monitoring, evaluation, response to patient needs and their preferences in most of the political documents and reports of health system of Turkey after the implementation of the health promotion plan in the country (20) and patient surveys to assess their satisfaction and expectations about public health care institutions in Singapore (21).

\subsubsection{Consensus}

Health cannot be regarded as merely a target for achieving which, the responsibility of executive system is suited to the ministry. Health is multi-sectorial and 
the product of dynamic and complex relationships. Solving complex issues requires organized approaches that cover a wide range of actors, levels of native-international governance, and community and individual participation. But in the range of action, there are major contradictions and inconsistencies between health and the benefits, values, goals, and performance of other policy-making areas; health is not the important priority for other sectors. The only realization about the fact that only the minister of health is responsible and accountable for health; and this claim has been confirmed with the neglect or absence of evidence of what actually happens or does not in practice (7).

Kickbusch and Behrendt in a study entitled "governance for health in the 21st century", introduced "health in all policies" as a network approach to policy-making across the state and an innovation in governance and, concluded that there is a need for institutional adaptation in response to a new and interconnected environment, especially about the consequences of globalization and the problem of the power balance between markets and governments. Their study focuses on the need to change the method of institutions work, admitting diverse interests and interests in the policy agenda, bringing together different actors (including representatives of the community, government and businesses), alliances and networks; which are described as "whole state" and "whole society" approaches. These terms, which are increasingly being used in national and international documents such as the European health outlook 2020 and the Helsinki declaration, the English-speaking countries of Australia, Canada, New Zealand, and the United Kingdom have used this style of governance and coordinated horizontal or vertical operations at various levels of government. In general, the "whole society" approach may begin with or without the "whole state" approach. The government is often a leader or facilitator, but a strong people-oriented organization or an organization's unity can take leadership, including civil society activities to tackle tobacco, AIDS and ... (22).

\subsubsection{Equal Rights (Equality)}

Sustainable welfare and tranquility in society will be possible for all people by recognizing equal rights. In the community, it needs to be ensured that individuals have shared the interests of the community proportional to their activity. In other words, everyone must have equal opportunities in good governance (2). Prioritizing and allocating resources in health systems should be based on health standards such as equality and justice (23). In recent decades, many countries have implemented programs to promote justice through the evolutions in the health system with the goal of welfare and health. For example, in Turkey, after the health promotion plan, the percentage of families with poverty due to health costs reaches to $0.3 \%$ in
2008 from $0.8 \%$ in 2003 (24). In the health system of Iran, after implementing the health promotion plan, the health insurance plan increases form $90 \%$ to $97 \%$ of the population; about $90 \%$ were urban residents among them. Following this plan, before 2014, people's pocket payments for hospital treatment costs were reduced from $37 \%$ to $5.4 \%$ for urban residents and $3 \%$ for rural residents (25). Studies have positively evaluated the results of these reforms in public satisfaction (26).

\subsubsection{Effectiveness and Efficiency}

The concept of the existence of quality and efficiency of providing services has been mixed with low cost and high productivity. However, in current care systems, there are serious challenges for quality and cost issues. Thus, using various methods such as, establishment of clinical governance and clinical guidelines in hospitals, use of referral system, establishment of electronic health system and family physicians, and many other measures try to improve quality and thus reduce costs of the health systems (27-30). In recent years, many efforts have been made in German health system to improve the quality of services and these efforts have led to increase public satisfaction and reduce costs. For example, nearly $90 \%$ of doctors have access to the electronic health record and use of this system is related to financial calculations, follow-up documents of laboratory data and quality assurance (31). In Sweden, in order to improve the quality of services in recent years, about 90 quality control sites have been established to monitor and evaluate the quality of services of providers and health centers and medical offices (29).

\subsubsection{Responsibility}

Responsibility can be considered as one of the key components of good governance. In addition to government agencies and institutions, private organizations and civil society organizations which are active in society should also be responsible for their policies and actions. It should be noted that the principles of good governance are interconnected in a chain and the implementation of each one requires the implementation of the other one. For example, without clarity and the rule of law, one cannot expect responsibility to be implemented in the society. (32).

\section{Discussion}

Adaptive studies about the health system in developing countries suggest that they are far apart from the systems exist in developed countries in achieving good governance in the health system $(3,7,8,32)$. Although in the health system of many countries, the rights of citizens in health affairs are well observed in the laws of the health system. However, the identified weaknesses in this 
assessment are weaknesses in participation and consensus orientation, justice and equity in determining community needs, responsiveness and clarity, the quality and efficiency of provided services and responsibility (33). Several studies have shown that the health system faces numerous challenges in many countries and requires major changes in governance method. In this regard, we can mention to some items such as: lack of clarity of information due to the lack of proper infrastructure for electronic health filing, use of inappropriate hardware, existence of various software systems in the hospital and the lack of unified data, weakness in the quality of primary health care and referral system, lack of clinical guidelines, lack of appropriate responsiveness at all levels of the health system, inadequate ability of staff in providing services, lack of transparency of programs and strategies of the ministry of health, weakness in the development of the attitude of intra-sectorial cooperation at different levels of the health system, weakness in the decision-making and policy making system due to lack of community participation, weakness in attracting the participation of the public to develop and implement the health system policy, lack of adaptation of annual budgeting with development programs, etc. (33-36).

Although, in recent years in the health systems of some countries such as Iran and Turkey, the payment from pocket of patients has significantly decreased with the implementation of health system changes. But given the lack of sustainability in resource supply and the inability of managers to provide expectations, the injection of financial resources with this process can provide a ground for widespread dissatisfaction that a real solution to the problems in this sector will be complicated and difficult at that time $(26,36)$. In addition, in centralized health systems where the cooperative role of the government, businesses and the people has been neglected, there are many challenges in three areas of service provision, production of resources and services that cover the area of service provision and the main sources of problems. Therefore, in order to resolve these challenges and achieve the highest levels of proper health, encouraging the social responsiveness of all public, private and non-governmental sectors, determining the structure of health services at the city and periphery of the cities, and adapting it to the family doctor program and the referral system, the evaluation of existing health programs, and the same actions would be effective (3).

\section{Conclusions}

In this study, we have concluded that favorable changes could be made in the health care system by analyzing governance in the health system of poor and developing countries (5). This study, by analyzing good governance in the health system, has tried to attract the attention of developing and poor countries to the importance of interaction and cooperation between health and non-health sectors, public and private sectors, and all citizens. So that, in the light of this interaction, they can provide a common and significant benefit to all, provide high-quality and low-cost services, and provide the satisfaction of all stakeholders in the health system through clarity and responsiveness (7). The belief that successful delivery of health care will require institutions and effective governance, has led to the attention toward the role of governance as a key element in providing practical solutions for strengthening health systems by government, academics officials and international providers. Accordingly, the suggestion is that the realization of health sector goals and policies requires a model of good governance in the health sector that can achieve a proportional movement with a comprehensive and systematic perspective (11). Although, in good governance, a series of principles and basic features of good governance are globally and internationally presented for all countries and governments, but it should be noted that operating and implementing them in different countries differ and the fact that, which works should be done and put in priority in a specific country is an issue that needs to be studied. Therefore, countries must identify and determine various dimensions of good governance with their national and native models, and for this purpose it is important to identify the historical experience of a country and its culture and its indigenous values.

\section{Acknowledgments}

This article is part of the Ph.D. dissertation about health services management of the Tehran University of Medical Sciences, Islamic Azad University, entitled “designing the good governance model in the health system of Iran". Thereby, we thank and appreciate all the loved ones who helped us in this way.

\section{Footnotes}

Conflict of Interests: There is no conflict of interests.

Ethical Consideration: The study was approved by the Research Center and Ethical Commitee of the Tehran University of Medical Sciences, Islamic Azad University as No. IR.IAU.SRB.REC.1397.086.

Funding/Support: There is no funding support.

\section{References}

1. Smajdor A, Bennett B. Health law's kaleidoscope: Health law rights in a global age. Oxford University Press; 2008. 
2. Avelino G, Barberia LG, Biderman C. Governance in managing public health resources in Brazilian municipalities. Health Policy Plan. 2014;29(6):694-702. doi: 10.1093/heapol/czt003. [PubMed: 23411119].

3. Makuta I, O'Hare B. Quality of governance, public spending on health and health status in Sub Saharan Africa: A panel data regression analysis. BMC Public Health. 2015;15:932. doi: 10.1186/s12889-015-2287-z. [PubMed: 26390867]. [PubMed Central: PMC4578603].

4. Houngbo PT, Coleman HL, Zweekhorst M, De Cock Buning T, Medenou D, Bunders JF. A model for good governance of healthcare technology management in the public sector: Learning from evidenceinformed policy development and implementation in Benin. PLoS One. 2017;12(1). e0168842. doi:10.1371/journal.pone.0168842. [PubMed: 28056098]. [PubMed Central: PMC5215885].

5. Smith MA, Spiggle S, McConnell B. Strategies for community-based medication management services in value-based health plans. Res Social Adm Pharm. 2017;13(1):48-62. doi: 10.1016/j.sapharm.2016.01.005. [PubMed: 26904962].

6. Abimbola S, Olanipekun T, Igbokwe U, Negin J, Jan S, Martiniuk A, et al. How decentralisation influences the retention of primary health care workers in rural Nigeria. Glob Health Action. 2015;8:26616. doi: 10.3402/gha.v8.26616. [PubMed: 25739967]. [PubMed Central: PMC4349907].

7. Brinkerhoff DW, Bossert TJ. Health governance: Principal-agent linkages and health system strengthening. Health Policy Plan. 2014;29(6):685-93. doi: 10.1093/heapol/czs132. [PubMed: 23411121].

8. Brinkerhoff DW, Fort C, Stratton S. Good governance and health: Assessing progress in rwanda. 2009.

9. Kirigia JM, Kirigia DG. The essence of governance in health development. Int Arch Med. 2011;4:11. doi: 10.1186/1755-7682-4-11. [PubMed: 21443766]. [PubMed Central: PMC3072323].

10. Siddiqi S, Masud TI, Nishtar S, Peters DH, Sabri B, Bile KM, et al. Framework for assessing governance of the health system in developing countries: Gateway to good governance. Health Policy. 2009;90(1):1325. doi: 10.1016/j.healthpol.2008.08.005. [PubMed: 18838188].

11. Pyone T, Smith H, van den Broek N. Frameworks to assess health systems governance: A systematic review. Health Policy Plan. 2017;32(5):710-22. doi: 10.1093/heapol/czx007. [PubMed: 28334991]. [PubMed Central: PMC5406767].

12. Mohammadi-Shahbolaghi F, Setare-Foruzan A, Hemmati S, Karimlu M. [Associated factors with community participation in health]. J Soc Welfare. 2013;13(48):47-72. Persian

13. Ghanei-Rad MA. [Theories of knowledge and structural characteristic of Iranian economy].J Sci Technol Policy. 2009;1(4):59-72. Persian.

14. Kumssa A, Mbeche IM. The role of institutions in the development process of African countries. Int J Soc Econ. 2004;31(9):840-54. doi: $10.1108 / 03068290410550638$.

15. Checkland K, McDonald R, Harrison S. Ticking boxes and changing the social world: Data collection and the new UK general practice contract. Soc Policy Admin. 2007;41(7):693-710. doi: 10.1111/j.14679515.2007.00580.x.

16. Blomgren $M$. The drive for transparency: Organizational field transformations in Swedish healthcare. Public Admin. 2007;85(1):67-82. doi: 10.1111/j.1467-9299.2007.00634.x.

17. Kaini BK. Healthcare governance for accountability and transparency. J Nepal Health Res Counc. 2013;11(23):109-11. [PubMed: 23787540].

18. Fund C. International profiles of health care systems. New York: Commonwealth Fund; 2010

19. Stokes J, Gurol-Urganci I, Hone T, Atun R. Effect of health system reforms in Turkey on user satisfaction. J Glob Health. 2015;5(2):20403. doi: 10.7189/jogh.05.020403. [PubMed: 26528391]. [PubMed Central: PMC4622488].
20. Graham WCK, Bilger M. Financing long-term services and supports Ideas from Singapore. Milbank Q. 2017;95(2):358-407. doi: 10.1111/14680009.12264. [PubMed: 28589606]. [PubMed Central: PMC5461396].

21. Senkubuge F, Modisenyane M, Bishaw T. Strengthening health systems by health sector reforms. Glob Health Action. 2014;7:23568. doi: 10.3402/gha.v7.23568. [PubMed: 24560261]. [PubMed Central: PMC4651248].

22. Kickbusch I, Behrendt T; World Health Organization. Implementing a health 2020 vision: Governance for health in the 21st century. Copenhagen, Denmark: World Health Organization; 2014.

23. Dundar M, Uzak AS, Karabulut Y. Healthcare in overview of Turkey. EPMA J. 2010;1(4):587-94. doi: 10.1007/s13167-010-0049-7. [PubMed: 23199111]. [PubMed Central: PMC3405350].

24. Assari Arani A, Atashbar T, Antoun J, Bossert T. Iran's health reform plan: Measuring changes in equity indices. Iran J Public Health. 2018;47(3):390-6. [PubMed: 29845027]. [PubMed Central: PMC5971176].

25. Iezadi S, Tabrizi JS, Ghiasi A, Farahbakhsh M, Gholipour K. Improvement of the quality payment program by improving data reporting process: An action research. BMC Health Serv Res. 2018;18(1):692. doi: 10.1186/s12913-018-3472-4. [PubMed: 30189897]. [PubMed Central PMC6128004].

26. Hashemi N, Farhani Nezhad S, Faghih A. [Evaluation of inpatient satisfaction from the implementation of the health system evolution program (HSEP)].J Prev Med. 2017;4(2):60-7. Persian.

27. Agha L. The effects of health information technology on the costs and quality of medical care. J Health Econ. 2014;34:19-30. doi: 10.1016/j.jhealeco.2013.12.005. [PubMed: 24463141]. [PubMed Central: PMC4415264].

28. Collins S, Piper KB, Owens G. The opportunity for health plans to improve quality and reduce costs by embracing primary care medical homes. Am Health Drug Benefits. 2013;6(1):30-8. [PubMed: 24991345]. [PubMed Central: PMC4031704].

29. Stanton R. Who will take responsibility for obesity in Australia? Public Health. 2009;123(3):280-2. doi:10.1016/j.puhe.2008.12.017. [PubMed 19232652].

30. Schmedding A, Rolle U. Decentralized rather than centralized pediatric surgery care in Germany. Eur J Pediatr Surg. 2017;27(5):399-406. doi: 10.1055/s-0037-1607026. [PubMed: 28958096].

31. Mikkelsen-Lopez I, Wyss K, de Savigny D. An approach to addressing governance from a health system framework perspective. $B M C$ Int Health Hum Rights. 2011;11:13. doi: 10.1186/1472-698X-11-13. [PubMed: 22136318]. [PubMed Central: PMC3247022].

32. Abbasi M, Rezaee R, Dehghani G. [Concept and situation of the right to health in Iran legal system]. Iran J Med Law. 2014;8(30):183-99. Persian.

33. Chan CQH, Lee KH, Low LL. A systematic review of health status, health seeking behaviour and healthcare utilisation of low socioeconomic status populations in urban Singapore. Int J Equity Health. 2018;17(1):39. doi: 10.1186/s12939-018-0751-y. [PubMed: 29609592]. [PubMed Central: PMC5879561].

34. Biglar M, Bastani P. [The challenges of stewardship in medical education system: A qualitative approach]. J Payavard Salamat. 2013;7(4):299-311. Persian.

35. Saghaiannejad Isfahani S, Zarei J, Ajami S, Saidbakhsh S. [The status of computerized medical records in selected hospitals of Ahvaz, Isfahan and Shiraz]. Health Inf Manag. 2012;8(6):784. Persian.

36. Evans DB, Etienne C. Health systems financing and the path to universal coverage. Bull World Health Organ. 2010;88(6):402. doi 10.2471/BLT.10.078741. [PubMed: 20539847]. [PubMed Central PMC2878164]. 